\title{
The Influence of Policy on Emotional Labour and Burnout among Further and Adult Education Teachers in the U.K.
}

\author{
https://doi.org/10.3991/ijet.v15i24.19307 \\ Walifa Rasheed-Karim \\ Bolton University, Bolton, England \\ Walifa.Karimegooglemail.com
}

\begin{abstract}
The Society for Education and Training (SET) regards maintaining wellbeing for teachers as important as it ensures the retention of staff and the progress of learners. A survey conducted with teachers reported various factors contributing to lack of wellbeing of teachers in further education (FE) and adult education [19]. Focus group interviews asked teachers in an FE college about equal opportunity, management, working conditions, staffing levels and career prospects and how they use emotions. For some, there is insufficient working space and time for breaks between lessons. They will take work home to complete, learners can be affected when staff are ill and supply staff are not employed due to funding so covering for existing staff imposes demands on them. Management policies lack practical application and promotion opportunities are restricted for some. This paper examines the extent to which existing policies shape the practice of teachers and whether this impacts on their wellbeing in terms of emotional labour and symptoms of burnout. Interviews reveal that teaching staff may suffer from panic attacks and anxiety and feel unsupported by heads of departments. However, they will maintain a professional exterior when interacting with learners. The impact of policy on work life-balance (WL-B) is discussed. Some teachers do not have sufficient time to spend with families and presumably interests and hobbies while more experienced teachers can separate family life from working life and so maintain a balance. The paper examines the adequacy of existing standards for staff seeking to maintain wellbeing.
\end{abstract}

Keywords_-FE/adult Ed. teachers; policy; wellbeing

\section{Introduction}

The Society for Education and Training (SET) in the U.K [19] conducted a survey with 1,000 SET members and reported that a number of factors contribute to the feeling of wellbeing among further education (FE) and adult education teachers. These are: good working relationships with colleagues, opportunities for professional development, professional autonomy in a supportive organisation and having good managers. Participants of the survey also completed the Warwick-Edinburgh Mental 
Wellbeing Scale, and this assessed the mental wellbeing of FE teachers and trainers. The scale revealed that they scored lower than the general population. Contributing factors affecting wellbeing of teachers were graded lesson observations, lack of autonomy/trust, lack of flexible working opportunities, poor decision making or practice by management. All had a negative impact on SET teacher members' wellbeing.

A link between stress, emotional labour and burnout in the FE/adult education sector was examined by Rasheed-Karim [18]. That is, older teachers, fifty plus, may feel exhausted due to, for example work demands, but interacting with students is not overly stressful. That is, they feel that they accomplish positive outcomes with students. It is evident that older teachers will use surface and deep acting appropriately in particular situations. This paper extends research and reports evidence from focus group interviews which show that there is sufficient reason to believe that existing polices with respect to current physical working conditions of part time and full-time teachers also contribute to emotional labour and symptoms of burnout.

Stated in the SET Issue [19], polices are generally created by government to meet current political aims. These are met with respect to such features as the distribution of learners and the size and nature of the workforce.

Given constraints, the government's intention would be to improve learner outcomes for the public. However, examination of policy does not always have a positive impact on the teaching workforce of $\mathrm{FE}$ and adult education. The extent and reasons for making this claim is examined in this paper. A summary of FE in terms of policy and practice was made [17].

'Adult providers as well as further and adult education colleges are a major part of an economically driven society improving skills for developing careers as well as for new interests and jobs. Further education (FE) colleges deliver courses that not only meet the demands of school leavers but also serve the wider community in terms of delivering higher education courses allied to universities. FE advocates the concept of 'inclusiveness', in terms of, for example, disabilities, ethnicity and race. This complies with the Equality Act [5], which points out that facilitating learning conditions for the vulnerable is essential. Additionally, staff should be appropriately trained to deal with issues such as the wellbeing of learners and day-to-day teaching (e.g. The Wolf Report, 2011 [21]; Ofsted, 2014; and the Society of Education and Training, 2017). However, this may be hampered by lack of resources to deal with such issues [6]. It is suggested there may be repercussions on the wellbeing of teaching staff, and this may have negative effects on work-family balance. The Education Support Partnership (2017) advise that the effects of exhaustion/burnout should not be underestimated. There is sufficient evidence to show that what policy intends to achieve is unachievable given the current climate of FE. One effect is that teachers may feel pressurised. How exhaustion and burnout is dealt with must be a joint effort between policy makers, researchers, teachers and managers.'

Some key words and terms are associated with the concept of 'wellbeing'. These are summarised: - 
Emotion: Emotions are complex cognitive structures linking feelings, thinking and action according to Averill [1] and lie at the core of teaching [10]. Others, such as Damasio [3] argued that the emotion-induction process releases a range of body and brain responses that lead to emotions. It could be argued that suppression of lesser felt emotions generates stress. However, when there is suppression of more deeply felt emotions such as anger, then it is envisaged that this will lead to emotional labour with students, colleagues and family [2].

Emotional Labour: Emotional labour was defined by Hochschild [11] with respect to the way people carry out their job roles in the workplace. In terms of the teaching profession, teachers will manage feelings to create emotional displays (either surface or deep acting) in exchange for a wage. Emotional labour also entails managing emotions when interacting with others at work. However, emotional labour is recognised as an occupational requirement which constitutes rules of how employees should feel/display with others. Emotional labour, while useful to the organisation, may have negative impacts for the employee. As emotions vary in intensity, more intense emotions will be more difficult to regulate, but how this is carried out is not yet clear [7].

Emotional Regulation: This includes the efforts to increase, maintain or decrease emotions ([8]; [13]). Displays of emotion affect the quality of service that organisations provide and so the capacity to make profit [11]. Emotion regulation occurs when emotions are not adequate for a given situation; people will influence the emotion's course. When emotional regulation takes place in the workplace, emotional labour is apparent as regulating emotions becomes a laborious activity [9].

Burnout: The conceptual framework assumes that in the event of a lack of adequate emotional regulation, burnout may ensue. The Maslach Burnout Inventory for Educators (MBI-E) measures three aspects of burnout: emotional exhaustion, depersonalisation and lack of personal accomplishment [15]. From the measurement of several items, three scores are achieved. The emotional exhaustion scale measures the extent to which individuals feel chronically tired. The depersonalisation scale assesses impersonal responses toward students. Finally, personal accomplishment measures the extent to which teachers feel they have achieved positive outcomes with their work with students.

Work-Life Balance (WL-B): As teachers manage the demands in the workplace and then face personal needs from family and in their lives, the home-work interface becomes problematic [20]. Emotional labour within the family involves managing the interpersonal domestic relationships, and spill over from work emotions will inevitably lead to stress [16]. For some, research instruments measuring WL-B are constructed by the researchers to answer their questions [12]. In a similar vein, the research instrument used in this research is created based on a literature survey.

\section{Methodology}

Focus group research from an FE college in England gathered information on policies with respect to equal opportunity, management, career plans, working 
conditions, staffing levels and WL-B. The focus groups (FG) were four: FG 1- two teachers; FG 2- two teachers; FG 3- five teachers; FG 4-five teachers. Quotes and discussions from the interviews are reported which exemplify the thoughts and experiences of staff members in the college. To further assess WL-B, a Qualtrics survey asked teachers to choose statements which they agree with. The paper examines the extent to which policies and practice impact on use of emotions and symptoms of burnout. The implication on work life-balance (WL-B) is discussed. All participants used pseudonyms and were asked to complete an ethics consent form.

\section{Results}

\subsection{Equal opportunity}

Figures reported from the Education and Training Foundation (ETF) surveys point out that approximately $11 \%$ of FE staff is from black and minority ethnic backgrounds (BAME) [14]. The figure points to less than $9 \%$ for senior managers. Mann is of the opinion that students do not see BAME role models among college staff, and this is especially pertinent in leadership roles. Significantly, there are no minority body representatives who can offer moral, social and economic support. It is recognised that BAME staff should be encouraged by organisations not to leave [14]. Furthermore, learning from successful practice on gender equality might safeguard the development of BAME leaders in the future [14].

Researcher: Do you think that equal opportunity policies are adequately implemented?

Sarah: Not really, I don't. I think they're OK for me on my behalf. I wouldn't really complain about any equal opportunities that are implemented within the department.

Stephanie: Yes, I think the department reflects our student cohort. We've got lots of, the staff, so we've got Asians, British so we've got all of the ethnicities. We've got Muslims. But our main aim is to enforce that even though we are, what's the word, we are different, we are at the same time equal and this is what we're trying to promote to our students. The only thing that has been brought up recently is that even though it reflects the staffroom, our staffroom reflects the student cohort, higher up in management, this is not the same. Apparently above us we've only got very few ethnic minorities. The other thing that I would like to, I don't know how important this is but we are currently, we've got 30 members of staff and only three of those are male and the rest are female. So, we find that bit unequal.

Jennifer: No. Equal opportunities aren't followed in our department, I don't think, as much as they should be. There's not enough inclusion for people with learning differences and yeah that's enough actually. Because staff aren't treated equally in any department probably and in this one especially. They're not given support when things are changing. We're not getting training for specific things we need to do. We're just expected to do it and we are sometimes discriminated against. 
It is evident that policies of equal opportunity applied to staff are dysfunctional. Teachers tend to form their own conclusions of how their department functions and conclusions about equal opportunities are generally negative.

\subsection{Management}

Researcher: How do management policies influence your job role?

Steve: Very supportive in some areas. Usually, management are involved in key areas, either budget holders who are involved in spending the money or staffing. If they decide that say more contracts can become available, then we can take in more contracted staff. But they also, they decide whether money can be allocated to certain areas so we can get new equipment or spend more money on transport or trips. So they're the people at our level, the teaching staff, we're not involved in the financial side of education but that's their job so they can really take a turn in whether we get more staff or not, whether we get new equipment or not or whether we get what we asked for.

Paula: Well, the policies are brought about aren't they as a form of protection and obviously a formula in which we are to actually comply. However, what's always written is always practical as to what can be enforced.

Nicola: And I think what's written, it's written by senior members of staff or HR members of staff that have nothing to do with teaching, have no comprehension of our job roles so policies that are enforced, I don't think a lot of these policies are appropriate for us.

Maise: I think sometimes yeah, I think probably, I don't know if it's on the right lines, but policies are introduced to kind of tick boxes, especially when like you've got inspections and so on. So, you're kind of, extra things get added on to make us kind of, it's like a paper trail isn't it sometimes, and extra things that you have to do.

Paula: I think there's far too much ticking boxes actually, we check, that hinders the form of our job really in a lot of ways because we have to tick a box but it's not always true to what we actually do.

To conclude, while management policies are supportive for some, they can hinder others as they do not apply to the reality of practice.

\subsection{Working conditions}

Researcher: Do your physical working conditions help you to maximise your potential in the workplace?

Sarah: Well, I don't know, like my physical ability in terms of lots of marking, we do as you can see, where we're situated ergonomically. We could be situated in a bigger space, I think. That can affect our physical ability.

Stephanie: Yeah, well we've got far too, our job space, as you can see, we're sharing desks. We haven't got enough space to place, do our marking or do our other tasks. A lot of our, we take a lot of our work home with us. For example, sessions last, one session can last three and a half hours and the students are given a fifteen-minute break but us staff are told that we can't leave the room, well we feel that we also need, 
could do with a ten-minute break to make use of the toilets, sometimes we would like to leave the room to eat something. We have very little lunch breaks. Our classes finish at 12:15 and the next class starts again at 1. By the time the students have all left and you've logged off, taken your stuff, done your register, fifteen minutes will have elapsed. Then you've been told by your head of area that you've got to be in class ten minutes prior to start time so there's only ten minutes to fifteen minutes for you to actually physically make it to the next room where you have to go, and have your lunch. Personally, myself as well as other members of staff, I find it extremely difficult to be able to eat, have a toilet break, have something to drink and physically move to another area where we have to teach.

Teachers generally feel that there is a lack of time for their main daily meals. Furthermore, there is insufficient desk space for completing tasks and so taking work home to compensate may cause lack of wellbeing among staff due to poor work lifebalance (WL-B).

\subsection{Staffing levels}

Researcher: To what extent do staffing levels affect your ability to work?

Carol: This is Foundation Learning. So, we're very low staffed, we're having to employ agency staff to do some of the teaching and we have got a member of staff who's off ill with anxiety and stress so we're having to cover classes and we've had to cancel some classes because we've just had nobody to cover them. So, it's pretty bad.

Paula: They don't really affect my role in the college or the department, to be honest, because we have staff really. It's just staff sickness. Because there's no funding, there's no money for part time staff like there used to be, then it impacts everybody because then we have to cover extra hours so you could have no desk duties for the week because you're just constantly teaching and that's the only time the level of staffing would really affect us.

Samantha: I think generally with the sickness as such, I think it does have an effect on us all in the sense of workloads because we do have heavy workloads because there's no, not only do we pick up the teaching but we pick up the administration. So, I think it's quite to our detriment.

In terms of staffing, teachers tend to cover when others are sick, and this seems to be due to stress and emotional labour experienced by sick staff. Teachers who cover class topics as well as teach their working hours may also suffer from exhaustion and this may endanger their responses and interactions with peers and students. Consequently, burnout may ensue.

\subsection{Career plans}

Researcher: How does your current job role influence your choices for future career plans?

Stephanie: I'm currently lecturer B. I've been doing this job for five years. As a lecturer B I'm a team, the leader of the team. However, I feel that after five years, there have been no opportunities for me to either move up in my career because above 
me is SEL and I've had to simply apply for other jobs, first of all because I'm not happy with the working conditions here and secondly because I felt that there was no other opportunities for me to climb up the career ladder so by the end of this month I will be officially leaving. And one of the reasons is because I'm not satisfied with the working conditions here.

Steve: Well, I've worked in various careers. I was a medic in the Air Force, I've worked in IT and then eventually worked in the fitness industry and then sort of did my degree, came into teaching and so this is my career now. I've been through enough other things and I've settled in and I've done this job for 18 years and I'll probably see it right through to retirement because I still enjoy the teaching side. I didn't really want to get promoted and end up sat in an office wearing a shirt and tie. I like teaching the learners so I'm quite happy to carry on doing what I'm doing.

Teachers who have had a varied career may be happier to remain in their current teaching post as it is a more satisfying choice in comparison to their other job roles. Younger staff whose main career is in teaching would want to progress speedily after a period of time in full time employment but may find this difficult for reasons such as lack of opportunities.

\subsection{Staff use of emotions and symptoms of burnout}

Researcher: Do you feel teachers genuinely experience the emotions they show?

Stephanie asserts that staff must suppress emotions and appear professional or according to Sarah deal with problems. She maintains that she does not show emotions. Stephanie explains that when students are threatening, the head of department thinks the student's behaviour is due to Stephanie's interaction with the student. She has panic attacks and suffers from anxiety.

Carol will display a professional exterior and is currently suffering from severe anxiety but does not let this impact on her learners. Nicole and Paula agree that they are all very professional and can scream/cry in the staff room, but this never impacts the classroom. They feel they have to build strong relationships with their learners and have a duty of care. They are empathetic with other teachers and feel they should be compassionate towards learners and staff.

Steve feels teachers genuinely experience the emotions they show. He said he is experienced and wants students to progress. Steve thinks that his job requires him to show emotions and he will speak about his experiences to students and this creates a bond between them. That is, Steve wants to explain student vulnerability through his experiences.

In summary, teachers can feel that they are blamed by heads of department because of negative attitudes from students and this affects them emotionally. However, they like to look professional and will hide negative emotions with learners, although they seek support in staff rooms where they show these emotions. 


\subsection{Work Life-Balance (WL-B)}

Researcher: Do you feel family responsibilities help/hinder you in the workplace? Please explain.

Stephanie thinks that family responsibilities hinder her and had she not been helped by her husband she would have been unable to do her job. Her husband takes their children to and from after school club. At work, she feels unsupported as a parent and says her job role does not meet the needs of parents. Sarah explains that teachers do not want to take work home because their role changes when they get home, from a teacher to housewife.

For Carol, family life helps her at work, but less time is spent with them and the family suffers as a result. Jennifer takes home some work as she needs to complete marking and planning tasks. This impacts on family life such as at times when there is a family loss and home responsibility clashes with her job role.

However, Paula explains that her experience at work has taught her to separate home from working life. She does take work home but says that new staff cannot 'switch-off' and so this impact on their home life.

Steve admits that he feels guilty devoting more time to his job than his family. That is, he spends more time looking after the health and welfare of other people's children and this makes him feel guilty at weekends, especially when he sorts out learners' work. Balancing work and other life commitments is difficult for him.

Survey data using online 'Qualtrics' from thirty-seven teachers of various FE and adult colleges reveal the following about WL-B.

Table 1. Percentage agreement of WL-B statements

\begin{tabular}{|c|l|}
\hline $\begin{array}{c}\text { Percentage (\%) } \\
\text { Agreement with } \\
\text { Statements }\end{array}$ & \multicolumn{1}{c|}{ Statements } \\
\hline $32.4 \%$ & Keeping family life and work loads manageable is difficult. \\
\hline $18.92 \%$ & $\begin{array}{l}\text { My spouse sometimes feels left out when I have too much to do such as } \\
\text { marking and this makes me unhappy in the workplace. }\end{array}$ \\
\hline $16.22 \%$ & $\begin{array}{l}\text { Relaxing with family helps me to be more focussed in solving problems at } \\
\text { work. }\end{array}$ \\
\hline Other: $13.51 \%$ & $\begin{array}{l}\text { Neither help/hinder } \\
\text { I don't suffer and have a good work/home balance. } \\
\text { My family are grown up and do not hinder. }\end{array}$ \\
\hline $8.11 \%$ & $\begin{array}{l}\text { I can help my children with homework and learn from the mistakes my } \\
\text { students make and this makes me a better worker. }\end{array}$ \\
\hline $8.11 \%$ & $\begin{array}{l}\text { I feel I get too emotionally involved with family and this makes me feel } \\
\text { emotionally drained at work }\end{array}$ \\
\hline $2.70 \%$ & I learn from my children and can manage a classroom. \\
\hline &
\end{tabular}

The data from the survey support the quotes from focus group interviews. That is, by not having an adequate rest period with family and doing things of interest outside work, for example hobbies, wellbeing of teachers may be affected in the workplace. This could have negative effects such as dealing with conditions of the workplace, interactions with students and addressing issues of lack of promotion opportunities. 
The consequence is that teachers feel unable to deal with policy and effects on practice effectively. The significance of not finding a balance between work and other life activity may result in symptoms of emotional labour and burnout.

\section{Conclusion}

Staff may feel that interaction between students and themselves must be emotionless when required as well as empathetic. This is necessary so that teachers gain an objective view of the needs of students and at the same time convey concerns to students that they understand their vulnerabilities. According to teachers, this helps students to progress. However, when teachers feel they are stressed due to, for example work demands, they will vent their frustrations in the staff room, where there may be peers who can offer support. Teachers show symptoms of burnout and this exhaustion is symptomatic of panic attacks and anxiety in an effort to remain professional in the classroom. Workloads and feeling of guilt, due to not having sufficient time for family may have negative emotional consequences in the workplace. Such experiences of regulating emotions and using emotional labour could also be indicative of existing policies of the college which reflect government needs. To summarise, teachers may feel they lack control over the demands found at work; are short-tempered; have panic attacks; absence from work likely; feelings of anxiety and exhaustion; lack time with children and detached from others. Various organisations have investigated ways of helping teachers maintain wellbeing.

The Education Support Partnership in the U.K [4] has advice for teachers on online blogs. The organisation suggests that teachers should set themselves goals such as learn how to play an instrument, attend gym twice a week or set a time to finish school each day during term time. The quotes in this paper, however, found that older teachers may have developed strategies to separate working life from home life and may be less prone to emotional labour and symptoms of burnout. However, SET (2019) point out that according to the Education and Training Foundation (EFT), onefifth of practitioners would like mental health training. The EFT has links with the Education and Support Partnership which offers a helpline for teachers and Mind's (U.K) Mental Health at Work portal offers support. Furthermore, a programme that aims to remove bias and obstacles to those seeking leadership roles in education and training, especially for BAME, is promoted by the Education and Training Foundation (ETF). However, it is suggested that many more colleges should have counselling services with links to the National Health Service. Additionally, those policies which cause teachers' lack of wellbeing should be addressed by representatives in the workplace.

\section{$5 \quad$ References}

[1] Averill, J. R. (1997). The emotions: An integrative approach. In R. Hogan, J. A. Johnson and S. R. Briggs (Eds.), Handbook of personality psychology (pp. 513-541). San Diego, CA, US: Academic Press. 
[2] Carlyle, D. \& Woods, P. (2003). Emotions of teacher stress. London: Trentham Books Ltd.

[3] Damasio, A. (2000). The Feeling of What Happens: Body, Emotion and the Making of Consciousness. Harcourt Brace, pp. 283-284. https://doi.org/10.26439/persona2000.n003. $\underline{1708}$

[4] Education Support Partnership (2017). Teacher wellbeing manifesto, pp. 2017-2022.

[5] Equality Act (2010) and schools: Departmental advice for school leaders, school staff, governing bodies and local authorities. Department for Education (2014).

[6] Field, J. (2015). Further education and the 12 dancing princesses. Journal of Vocational Education and Training, 67(4), 597-598. https://doi.org/10.1080/13636820.2015.1106751

[7] Grandey, A.A. Diefendorff, J.M. \& Rupp, D.E. (2013). Emotional labour in the 21st century: Diverse perspectives on emotional regulation at work. London: Routledge. https:// doi.org/10.4324/9780203100851

[8] Gross, J.J. (2002). Emotion regulation: Affective, cognitive, and social consequences. Psychophysiology, 39, 281-291. https://doi.org/10.1017/s0048577201393198

[9] Gross, R., Mcllveen, R., Coolican, H. Clamp, A. \& Russell, J. (2000). A New Introduction for A level, 2nd edn. London: Hodder and Stoughton.

[10] Hargreaves, A. (1998a). The emotional practice of teaching. Teacher and Teacher Education, 14(8), 835-854. https://doi.org/10.1016/s0742-051x(98)00025-0

[11] Hochschild, A.R. (1983) The Managed Heart: Commercialisation of Human Feeling. Berkeley: University of California Press.

[12] Irfan, A. \& Azmi, F.T (2015). Work Life Balance among teachers: An empirical study. Journal of Business and Management, 17 (2), 1-11.

[13] Levenson, R.W. (1999). The intrapersonal functions of emotion. Cognition and Emotion, 13(5), 481-504. https://doi.org/10.1080/026999399379159

[14] Mann, R.K. (2019). Policy Review: FE missing out on BAME talent. In Tuition, Society for Education and Training, 38, 7.

[15] Maslach C, Jackson S.E \& Leiter M.P (2016). Maslach Burnout Inventory Manual. Palo Alto, CA: Consulting Psychologists Press Inc.

[16] Morgan, D.H.J. (1996:131). Family Connections: An Introduction to Family Studies. Cambridge: Polity Press.

[17] Rasheed-Karim, W. (2018). Wellbeing, policy and practice among further education Teachers. Psychology Teaching Review, 24 (1). Publication of the British Psychological Society's Division of Academics, Researchers and Teachers in Psychology.

[18] Rasheed-Karim, W. (2020). The effects of stressful factors, locus of control and age on emotional labour and burnout among further and adult education teachers in the U.K. Proceedings of the 2nd International Conference in Education, St Anne's College, Oxford University, U.K.

[19] Russel, D. (2019). Getting policy right is about hitting the sweet spot between different requirements. In Tuition, Society for Education and Training, 38, 6.

[20] Wallace, S. (2007). Managing behaviour in the lifelong sector. London: Sage.

[21] Wolf, A. (2011). Review of vocational education- The Wolf Report: Forwarded by the secretary of state for education, Michael Gove MP.

\section{$6 \quad$ Author}

Walifa Rasheed-Karimis an associate fellow of the British Psychological Society, a chartered psychologist, and a chartered scientist. She is a support tutor for higher education students with Special Educational Needs and a teacher in further education.

Article submitted 2020-10-19. Resubmitted 2020-11-25. Final acceptance 2020-11-26. Final version published as submitted by the authors. 